\title{
Penerapan Bandwidth Management Untuk Dynamic User Pada Mikrotik Menggunakan Per Connection Queue (PCQ)
}

\author{
M. Agus Syamsul Arifin \\ Program Studi Sistem Komputer, Sekolah Tinggi Ilmu Manajemen dan Komputer Musi Rawas \\ Lubuklinggau, Sumatera Selatan \\ agus1988@gmail.com
}

\begin{abstract}
Simple Queue is a solution that is most convenient for use in performing Bandwidth Management by entering the amount of bandwidth that will be used and the IP address to be restricted bandwidth. Problems will arise if it turns out the number of users that there is a user with a considerable amount. Not to mention if the User is Dynamic. Users can be connected or disconnected at will the user. It would be very inconvenient if you had to make Simple Queue individually for each user. One way that can be used to overcome this problem is by PCQ (Per Connection Queue), PCQ is one way of doing that is easy enough bandwidth management where $P C Q$ works with an algorithm that will divide evenly bandwidth to a number of users are active. Ideal PCQ be applied if the difficulty in determining the setting Bandwidth Bandwidth per User. How it works is by adding PCQ sub-queue, based on a certain classification by entering the amount of their bandwidth Upload and Download. PCQ split evenly banwidthkesetiap User.
\end{abstract}

Keyword:Bandwidth Management, MikroTik, Per Connection Queue (PCQ)

\begin{abstract}
Abstrak
Simple Queue adalah sebuah solusi yang paling mudah untuk di gunakan dalam melakukan Bandwidth Management dengan mengisikan jumlah Bandwidth yang akan di gunakan dan alamat IP yang akan di batasi Bandwidthnya. Permasalahan akan muncul jika ternyata jumlah User yang ada merupakan User dengan jumlah yang cukup banyak. Belum lagi jika User tersebut bersifat Dynamic. User dapat tersambung atau punter putus sesuai kemauan User. Akan sangat merepotkan jika harus membuat Simple Queue satu per satu untuk setiap User. Salah satu cara yang dapat digunakan untuk mengatasi permasalah ini adalah dengan PCQ (Per Connection Queue), PCQ merupakan salah satu cara melakukan manajemen Bandwidth yang cukup mudah dimana $P C Q$ bekerja dengan sebuah algoritma yang akan membagi Bandwidth secara merata kesejumlah User yang aktif. PCQ ideal diterapkan apabila dalam pengaturan Bandwidth kesulitan dalam penentuan Bandwidth per User. Cara kerja PCQ adalah dengan menambahkan Sub-Queue, berdasar klasifikasi tertentu dengan memasukkan jumlah besaran Bandwidth Upload dan Download. PCQ membagi Banwidth secara merata ke setiap User..
\end{abstract}

Kata kunci: Bandwidth Management, MikroTik, Per Connection Queue (PCQ). 


\section{PENDAHULUAN}

Jaringan komunikasi elektronik yang menghubungkan jaringan komputer dan fasilitas komputer yang terorganisasi di seluruh dunia melalui telepon atau satelit [1]. Dalam perkembangannya internet memberikan pengaruh besar terhadap cara penyebaran informasi dimana sekarang dengan adanya internet informasi bisa di dapatkan dengan mudah. Perangkat router yang digunakan menggunakan Mikrotik, MikroTik RouterOS ${ }^{\mathrm{TM}}$ adalah sistem operasi dan perangkat lunak yang dapat digunakan untuk menjadikan komputer manjadi router network yang handal, mencakup berbagai fitur yang dibuat untuk ip network dan jaringan wireless, cocok digunakan oleh ISP dan provider hotspot [2].

Dalam Jaringan Komputer Manajemen Bandwidth merupakan hal yang sangat penting karena berkaitan dengan kepuasan pengguna dan kehandalan sistem jaringan tersebut dalam melayani User yang terhubung ke dalam jaringan tersebut. Permasalahan yang sama terjadi pada penelitian yang dilakukan Mirsantoso, Toibah Umi Kalsum, Reno Supardi (2015) yaitu kesulitan dalam mengontrol penggunaan Bandwidth untuk user dengan jumlah yang banyak [4].

Simple Queue adalah sebuah sebuah cara yang paling mudah untuk di gunakan dalam melakukan Bandwidth Management dengan mengisikan jumlah Bandwidth yang akan di gunakan dan alamat IP yang akan di batasi Bandwidthnya untuk setiap User. Oleh karena itu pada penelitian ini dikukan untuk membahas tentang management bandwidth menggunakan Per Connection Queue, PCQ merupakan salah satu cara melakukan manajemen bandwidth yang cukup mudah dimana PCQ bekerja dengan sebuah algoritma yang akan membagi bandwidth secara merata kesejumlah client yang aktif. PCQ ideal diterapkan apabila dalam pengaturan bandwidth kita kesulitan dalam penentuan bandwidth per client [3]. Simple Queue adalah sebuah fitur yang ada di dalam Mikrotik yang berguna untuk membagi banwidth ke setiap User [5]. PCQ membagi Bandwidth secara merata tergantung jumlah user yang terhubung ke dalam jaringan sehingga metode ini sangat berguna untuk sebuah jaringan komputer yang usernya bersifat mobile.

\section{METODE PENELITIAN}

Metode penelitian yang digunakan adalah metode eksperimen dimana pada penelitian ini dilakukan perancangan sistem, implementasi dan pengujian. Perancangan Sistem di lakukan untuk menyesuaikan kebutuhan yang akan di gunakan pada sistem setelah di tentukan kebutuhan yang sistem yang akan di gunakan kemudian dilakukan tahap implementasi, pengujian dilakukan untuk mengukur kinerja protocol PCQ yang kemudian hasil pengujian di dokumentasikan untuk di analisis kemampuan protocol ini dalam mengatasi masalah penggunaan Bandwidth untuk user yang selalu berubah - ubah dan banyak. Dari hasil analisis akan di dapatkan kesimpulan apakah protocol PCQ ini dapat di terapkan pada sistem di tempat penelitian atau tidak.

\subsection{Rancangan Sistem}

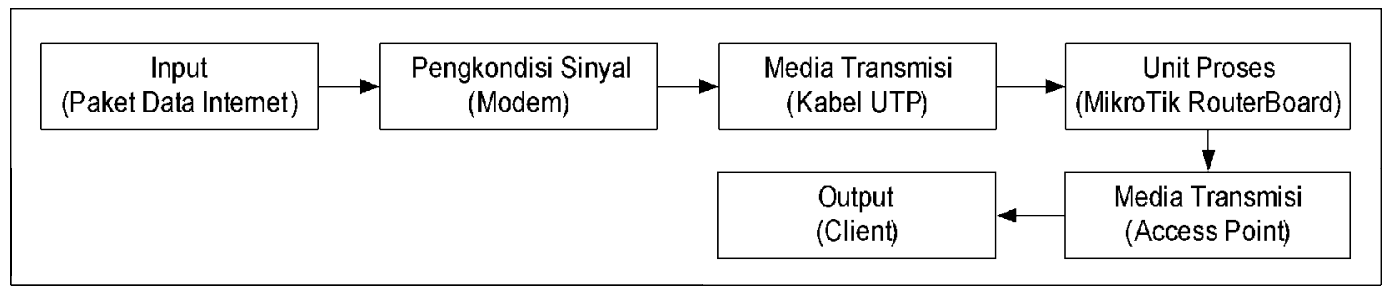

Gambar 1. Blok Diagram Sistem 
Cara kerja PCQ adalah dengan menambahkan sub-queue, berdasar classifier tertentu. Berikut gambaran cara kerja PCQ dengan parameter PCQ-Rate $=0$.

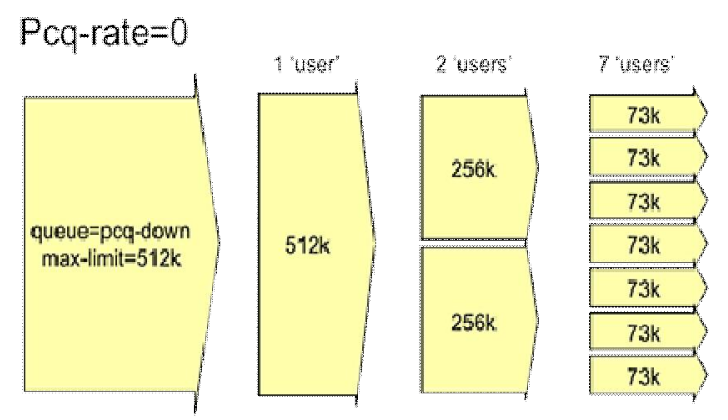

Gambar 2. Cara Kerja PCQ [5]

Proses perancangan sistem meliputi instalasi dan konfigurasi sistem. Arsitektur jaringan sistem ini dibangun dengan menggunakan tipe client-server. Router yang digunakan adalah Routerboard CCR1009-8G-1S-1S+.

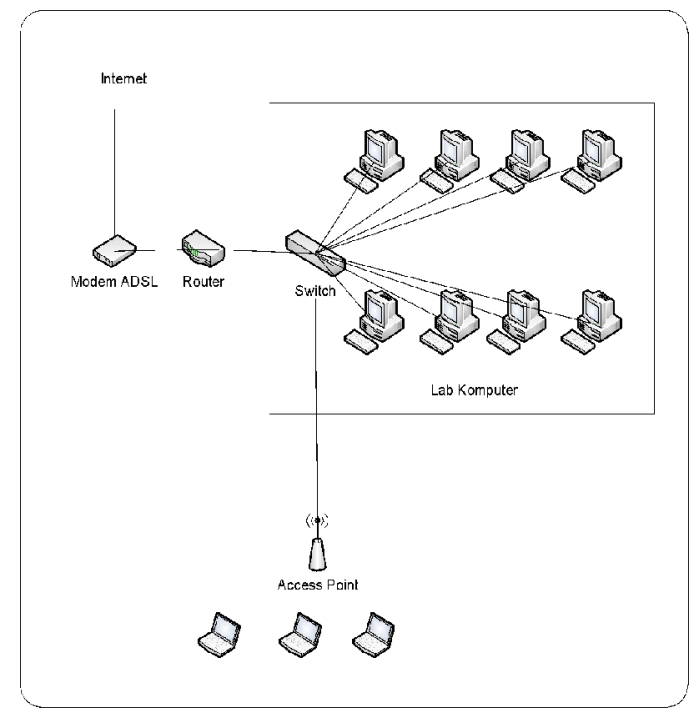

Gambar 3. Topologi Jaringan yang Akan Menggunakan PCQ

\section{HASIL DAN PEMBAHASAN}

\subsection{Hasil}

Hasil dari sistem ini merupakan suatu management bandwidth dengan membagi bandwidth yang ada sama rata berdasarkan banyaknya pengguna (User). Dalam hal ini, setiap user akan dialokasikan bandwidth yang sama tergantung dari banyaknya user. Semakin banyak user yang menggunakan jaringan bandwidth, maka akan semakin kecil bandwidth yang didapat oleh user. Dan sebaliknya, semakin sedikit user yang menggunakan bandwidth jaringan, akan semakin besar pula bandwidth yang di dapat oleh user. 


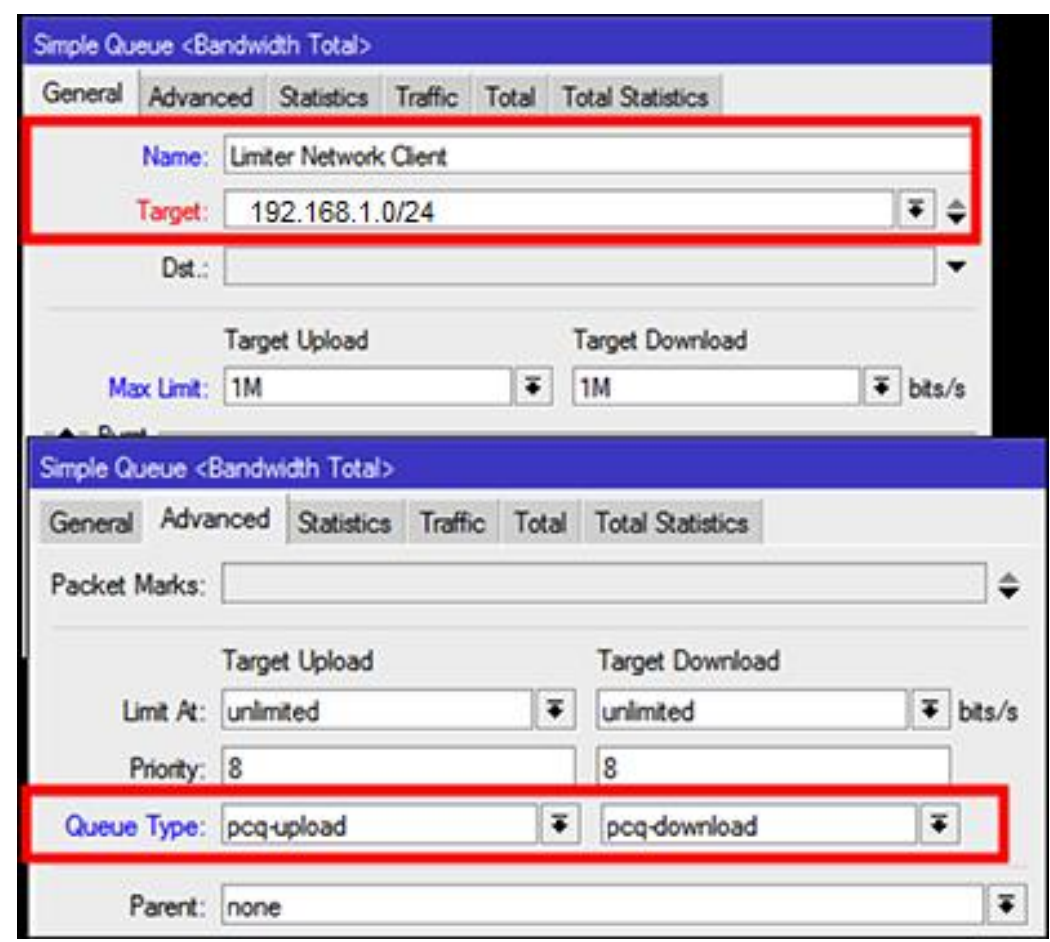

Gambar 4. Komfigurasi PCQ pada Simple Queue

\begin{tabular}{|c|c|c|c|}
\hline \multicolumn{3}{|c|}{ 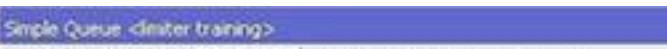 } & $\square \times$ \\
\hline Generd Advanced & 1) Sabiotics Traffic Total & ToLd STORistiks & ok \\
\hline \multirow{2}{*}{ Avg. Rote: } & Torget Uplasd & Target Dounlload & Concel \\
\hline & $92.4 \mathrm{kbos}$ & $802.5 \mathrm{kbos}$ & Apply \\
\hline \multirow[t]{2}{*}{ Ave-Podat Rote: } & 115 & 110 & \\
\hline & & & Descotio \\
\hline Queued Bytes: & & $81.7 \mathrm{~KB}$ & Coerment \\
\hline Queved Packets: & & 66 & $\cos y$ \\
\hline Bytes: : & $27.8 \mathrm{MB}$ & $169.7 \mathrm{MB}$ & Remove \\
\hline Pockets: : & $210 \$ 28$ & $2055 s$ & Roset Counters \\
\hline Dresped: : & 25 & 3796 & Reset As Courkers \\
\hline Lends: : & 601 & 83 & Torch \\
\hline Ecerous: : & 209927 & 205254 & \\
\hline ACQ Queves: & 30 & 32 & \\
\hline \multicolumn{2}{|l|}{ enabled } & & \\
\hline
\end{tabular}

Gambar 5. Hasil Pengujian Sistem Setelah Diterapkannya PCQ

\subsection{Pembahasan}

Dari hasil yang telah didapat terhadap pada tahapan implementasi dan pengujian, dapat dinyatakan bahwa perancangan managemen bandwidth berjalan dengan baik. Berdasarkan hasil pengujian terhadap 8 (delapan) user dengan bandwidth sebesar 1 Mbps menunjukkan paket data yang diterima $u$ ser adalah sebagai berikut:

Avarage Upload Packet Rate

Avarage Download Packet Rate

$$
\begin{aligned}
& =115 \mathrm{Kbps} \\
& =110 \mathrm{Kbps}
\end{aligned}
$$


Dengan perhitungan secara manual, artinya bandwidth sebesar 1 Mbps di bagi dengan banyaknya user:

Average Bandwidth per User

$$
\begin{aligned}
& =\text { Max. } \text { bandwidth } / \text { Jumlah User } \\
& =1024 \mathrm{Mbps} / 8 \\
& =128 \mathrm{Kbps}
\end{aligned}
$$

Dengan membandingkan hasil pengujian dan perhitungan manual, maka didapat data yang menunjukkan pendekatan hasil. Untuk rata-rata data upload sebesar $115 \mathrm{Kbps}$. Dan ratarata data download $110 \mathrm{Kbps}$. Selisih hasil keduanya tidak menunjukkan hasil yang signifikan, yaitu berkisar antara $10-20 \mathrm{Kbps}$. Selisih ini bisa disebabkan karena bandwidth yang diterima dari ISP (Internet Service Provider) tidak penuh sebesar 1 Mbps.

\section{KESIMPULAN}

Penerapan management bandwidth untuk dynamic user menggunakan PCQ merupakan salah satu solusi untuk mengatasi masalah pembagian Bandwidth pada sebuah Jaringan Komputer yang memiliki banyak pengguna yang akan kesulitan apabila menggunakan Simple Queue. PCQ (Per Connection Queue) memungkinkan untuk membagi bandwidth yang ada menjadi sama besar untuk masing-masing user dengan menggunakan algoritma khusus yang ada di mikroTik Routerboard. Dengan menggunakan PCQ seorang administrator jaringan tidak perlu membagi bandwidth secara manual dengan mengisi nilai bandwidth upload dan upload untuk setiap User. PCQ membagi Bandwidth secara merata tergantung jumlah user yang terhubung ke dalam jaringan sehingga metode ini sangat berguna untuk sebuah jaringan komputer yang usernya bersifat mobile.

\section{SARAN}

Dalam penelitian ini jumlah user yang digunakan hanya berjumlah 8 user, untuk penelitian selanjutnya dengan tema yang sama diharapkan menggunakan jumlah user yang lebih banyak untuk menguji kehandalan protokol PCQ ini.

\section{DAFTAR PUSTAKA}

[1] Sofana Iwan. 2013, Membangun Jaringan Komputer, Informatika, Bandung.

[2] Sofana Iwan. 2017, Jaringan Komputer berbasis MikroTik, Informatika, Bandung.

[3] MikroTik (http://www.mikrotik.co.id Diakses 2 Mei 2017)

[4] Mirasantoso, dkk. 2015. Implementasi dan Analisa Per Connection Queue (PCQ) Sebagai Kontrol Penggunaan Internet pada Laboratorium Komputer. Jurnal Media Infotama, XI (2), $139-148$

[5] Mikrotik Documentation (https://wiki.mikrotik.com/wiki/Manual:Queues_-_PCQ Diakses 1 Juni 2017) 